\title{
APRENDER SOBRE AS CULTURAS INDÍGENAS NA ÉPOCA COLONIAL: A GÊNESE DO LIVRO DE VIAGEM DE HANS STADEN (HISTORIA, 1557) NO CRUZAMENTO DE DISCURSOS ALHEIOS
}

\author{
Franz Obermeier \\ Universität zu Kiel
}

Resumo: O livro do alemão Hans Staden, Warhaftige Historia, o primeiro publicado sobre o Brasil em 1557, é uma fonte primária para o nosso conhecimento do Brasil colonial e da civilização indígena, sobretudo dos Tupinambás. O artigo tenta mostrar que o livro é baseado em observações verídicas, mas que em partes importantes responde também a discursos alheios, julgamentos da época sobre os indígenas e concepções religiosas sobre os nativos da colônia.

Palavras-chave: Hans Staden Warhaftige Historia; Duas viagens ao Brasil, Marburg; Marburgo 1557

\section{Metodologia}

Temos hoje a tendência de reconstruir a visão social de um personagem retrospectivamente como uma ideologia e uma gama de convicções, observações e regras de conduta, atitudes e reticências inconscientes. Numa biografia se aceita pelo menos um conceito abstrato de desenvolvimento pessoal que muitas vezes tende a construir uma convicção que as pessoas mesmas não formulavam assim ou simplesmente não eram conscientes em muitos elementos. Para a maioria dos textos literários não dispomos de informações bibliográficas sobre o autor e isso talvez seja bom porque a interpretação biográfica de obras literárias foi, na maioria das vezes, baseada numa simplificada equação pouco velada entre vivências pessoais e obras literárias que, na maioria dos casos, ofuscou a 
análise estrutural dos textos.

O texto literário é um produto de várias fases de trabalho e nos vem como através de um filtro. Nos livros de viagens ainda temos o problema metodologicamente pertinente que os textos têm uma referência concreta a fatos vividos e transmitidos na escritura. A reconstrução da percepção dos viajantes não é possível, mesmo se em alguns raros casos temos duas pessoas que descrevem a mesma viagem e podem confirmar fatos e observações, ficamos sempre restringidos a fatos externos (qualidade e valor dos textos, respeito a regras de gêneros, expectativas do público leitor, transmissão material do texto). Basta aqui lembrar que um texto fundamental como o diário de bordo de Colombo nos foi conservado só numa reescritura de Bartolomé de las Casas. Em todos os textos de viagens, que pertenciam na época das descobertas ao gênero da historiografia (gênero médio na terminologia retórica), a abordagem permite uma metodologia da verificação de confrontação de várias fontes, um método que também deixa um fator marginal de não poder confirmar o conjunto de observações e, ainda menos, as interpretações dos personagens na função bipolar de escritor e de narrador. Tem-se visto os limites de uma confrontação na discussão do fenômeno da antropofagia que, como cada pesquisa etnológica no terreno, sempre implica um fato de observação não verificável pelos leitores posteriores e ligado, na maioria das vezes, a uma condenação fundamental que tem falsamente levado alguns autores a duvidar das observações dos primeiros cronistas e viajantes, vendo neles enganadores que quiseram transmitir uma imagem negativa dos povos ou vítimas de uma insuficiência de documentação.

No caso de Staden se tem quase uma focalização em vários problemas metodológicos que também fazem da interpretação desse texto não só fundamental para a historiografia do Brasil, mas para o desenvolvimento do livro de viagem no século XVI um desafio para pesquisadores de vários campos, como etnólogos, historiadores e especialistas de literatura de viagem.

\section{Staden e o seu pré-texto}

$\mathrm{Na}$ minha contribuição quero aqui compreender alguns fatores genéticos do texto que são inteiramente ligados ao problema da autenticidade, mas têm também um valor para a estruturação do livro num contexto da discussão sobre culturas indígenas do século XVI, que tinham um impacto maior sobre a escritura de muitos autores da época. Essa influência abrangia a maneira de escrever e a escolha de elementos estilísticos e até indiretamente os 
fatos narrados e a profundidade dos detalhes transmitidos. Na falta de outros documentos manuscritos ou julgamentos dos contemporâneos da época podemos apenas reconstruir o trabalho de Staden com a ajuda da comparação com outros livros de viagens da época, mas essa reconstrução torna-se possível tendo em vista o grande número de fontes disponíveis sobre os Tupinambás. Esse trabalho também ajudará a reconstruir o lugar e a originalidade do livro de Staden num amplo discurso do século XVI sobre o Brasil e pôr em relevo a sua originalidade e a razão do seu sucesso editorial até os nossos tempos.

O discurso da época sobre o Brasil é transmitido por meio de vários outros documentos que falam sobre o mesmo tema, crônicas, documentos administrativos, tratados, ilustrações e cartas. Staden se insere também em tradições literárias da época como tenho mostrado com detalhes na minha introdução à edição crítica de 2007 (Kiel, Editora Westensee), sobretudo ao discurso edificante que é visível no nível textual em certa temática religiosa e figuras de estilo que Staden usa com frequência. A ligação entre intenção textual do autor, escolha do material e estilística do trabalho literário e julgamento moral da época sobre os povos desconhecidos deve estar no centro de uma compreensão do texto. Não só o conteúdo claramente formulado de um texto em certas passagens, como também a maneira de transmitir esse discurso num trabalho literário, feito de um uso consciente de figuras estilísticas e de intervenções de um autor interno ao texto, nos ajuda a mostrar a ideia mesma de Staden sobre os índios do Brasil. Ele quis transmiti-la em sua engenhosa obra aos leitores, primeiramente aos seus contemporâneos, depois a leitores de outros países e, posteriormente, até a nós.

\section{O discurso alheio}

Poucos documentos portugueses sobre o Brasil foram publicados na época e o acesso de Staden a manuscritos sobre o Brasil é improvável. É central outro aspeto: se existe sempre um discurso oral a atender, mesmo que poucos autores tematizem esse problema sobre as fontes da sua informação. Essa discussão é naturalmente ligada a outra questão que valoriza o texto de Staden para conhecer o seu Brasil, questão epistemológica sobre a autenticidade de um documento segundo o nosso julgamento e também a compreensão literária de limites e méritos de uma obra que passa a ser um dos textos fundadores da história colonial do Brasil.

Os etnólogos do início do século XX que primeiro reconheceram o valor das observações de Hans Staden tinham tendência a reconstruir com as poucas fontes da época uma 
visão global da cultura indígena Tupinambá ou Tupi-Guarani (por exemplo, os dois estudos maiores de Métraux publicados em 1928) baseando-se no máximo das observações escritas, picturais ou outras que se tinha. A influência de certo estruturalismo etnográfico na obra de Florestan Fernandes teria o mesmo efeito alguns decênios depois, por exemplo, no seu célebre artigo sobre a estrutura do canibalismo dos Tupinambás (1952). O valor intrínseco dos livros de viagens, a sua estrutura própria e a contingência histórica foram raramente tematizados. Foram uma fonte com material para o próprio trabalho e a documentação sobre uma tribo virtualmente abstraída de julgamento de valores da época e dos documentos singulares. Mas esse discurso de um autor não é sempre homogêneo, responde a outras ideias da época.

Usando a terminologia de Bakhtin, célebre teórico russo da literatura, do "discurso alheio" se pode ressaltar certos julgamentos e a sua posição num mapa mental de Staden mostrando-se no seu livro.

\section{Pré-texto e produção de um texto: o Prefácio de Dryander: o caso clássico da integração de um discurso alheio aos próprios fins}

Sabemos pouco sobre as circunstâncias exteriores da produção do livro de Staden. O professor Johannes Dryander da Universidade de Marburgo, médico e autor de vários livros (de fato se chamou Eichmann, 1500-1560), autor do prefácio, menciona nesse texto os relatos orais de Staden antes do seu soberano, o Landgrave Felipe de Hesse. O papel de Dryander, visto por alguns até como autor do livro de Staden, foi certamente o que admitia a si mesmo: era limitado a correções; ele ajudou também, certamente de modo restrito, a evitar erros geográficos e quis contribuir com o seu prefácio para confirmar a autenticidade do livro, preceito típico para documentos fidedignos na época do humanismo. Fato de maior destaque é que ele foi, na época, o censor oficial da produção literária de Marburgo. Constatamos que Dryander usa no seu prefácio até uma fórmula oficial (no original o verbo "durchgesehen", literalmente "olhar através" no sentido de "examinar") que provém dos regulamentos da censura organizada, sem a qual nenhum livro podia ser publicado em Marburgo, visto a experiência com o panfletismo antiprotestante durante as guerras da religião de católicos contra protestantes. Até agora tem-se descuidado totalmente sobre esse papel de censor

\footnotetext{
${ }^{1}$ Problemy tvorčestva Dostoevskogo, 1929, na versão revisada com o título Problemy poètiki Dostoevskogo, 1963. Em francês: La poétique de Dostoiëvski de Mikhaïl Bakhtine, trad. de Isabelle Kolitcheff, Paris: Éd. du Seuil 1998.
} 
incumbido a Dryander, não considerando as condições exteriores de uma produção de um livro no século XVI. Mas Dryander também era amigo pessoal da família de Staden (ele e o pai de Staden são oriundos do mesmo lugar do norte de Hesse, chamado Wetter, lugar de uma escola de latim célebre na Idade Média) e tinha, também por isso, um certo interesse em ajudar Hans Staden.

Essa influência pode parecer exterior, mas nos ajuda a perceber mais distintamente o papel de Dryander, sem o exagero injustificado de pesquisadores que quiseram desqualificar o valor do livro de Staden. Ressaltamos, numa perspectiva genética, o desenvolvimento da história entre versão oral apresentada oficialmente ao Duca Philipp, Landgraf von Hessen, que na concepção protestante era - lembramo-nos - também a autoridade teológica instituída por Deus e, por esse motivo, suas pesquisas tinham também um valor de exame da autenticidade. É de se supor que Dryander organizou também esse encontro com o Duca.

Não sabemos com detalhes quais marcos distintivos essa versão oral tinha. Comparando com os dois únicos documentos exteriores ao texto de Staden, de sua autoria, que são duas cartas escritas na entrega do livro a outros nobres (ver Menk, 1989), podemos supor que certamente a versão contada continha já a interpretação religiosa da sua experiência, também encontrada nessas duas cartas. O contexto religioso do livro e da época nos permite pensar que essa concepção certamente correspondia à autointerpretação da pessoa histórica Staden que transparece através do seu narrador/escritor "Staden" como função textual. Os protestantes da época viram na história uma coleção de exemplos da ação divina e uma prova da eleição da graça divina. Staden propunha essa leitura de maneira simplificada, conforme os livros populares e muito de acordo com as ideias católicas vigentes entre muitos dos seus leitores, mas em visível revestimento protestante.

\section{A escritura de Staden e do seu contemporâneo Ulrich Schmidel: maravilhas ou neutralidade?}

A comparação desse trabalho do narrador/autor anterior com outro livro da época, o livro de Ulrich Schmidel sobre seu tempo como soldado no Rio de la Plata (1536-1553), nos mostra que essa apresentação oral das próprias experiências podia certamente ter um impacto no texto posteriormente escrito porque alguns leitores esperavam que fossem levadas em conta suas críticas, uma vez que os autores o faziam considerando certas expectativas do leitor de livros de viagens. O forte direcionamento da escritura do livro, que versa a receptividade e 
a insistente discussão intratextual da autenticidade, pode também ser visto como resposta a críticas possíveis do que se poderia chamar o récit de Staden antes do discurso oficial impresso no livro. No caso de Schmidel, temos indicações no próprio texto e também podemos reconstruir através de censuras na organização do texto (ver Schmidel, edição crítica por Obermeier, 2008, e minha contribuição nas atas de Heidelberg (ainda não publicada). Uma descrição dos "mirabilia" (maravilhas), sobretudo na observação fantástica de animais, procedimento bem conhecido na época medieval e da Renascença, foi inserida na obra de Schmidel como descrição de uma enorme serpente, posteriormente ao texto já acabado, numa folha numerada separadamente ao autógrafo de Schmidel - hoje conservado na biblioteca Württembergische Landesbibliothek de Stuttgart. Portanto, Schmidel se nega a ver no caiman um basilisco, monstro da Idade Média, confrontação que faziam os primeiros copistas dos seus manuscritos (Schmidel, ed. Obermeier 2008, p. 172). Staden se negava a esse discurso e se limitou à inclusão de alguns capítulos do segundo livro com observações de animais. ${ }^{2}$

Para Dryander, seu prefácio foi um trabalho de circunstância, uma contribuição para um amigo, um livro que, em todos os casos, servia como censor e deveria ser lido. Prefácios a livros foram um trabalho importante nas edições críticas de livros clássicos e Dryander dedica o seu prefácio a outro nobre (não o soberano de Staden a quem dedicou o livro, mas ao duca Felipe, Conde de Nassau e Saarbruecken). Dedicatórias na época foram normalmente gratificadas com uma recompensa em dinheiro. No caso de Staden, que voltou do Brasil sem grandes recursos financeiros, pode-se pensar que um posto na administração do landgrave teria sido certamente uma finalidade ideal para ele que, infortunadamente, não alcançou. Dryander morreu alguns anos depois da edição de Staden, publicada em 1560, e não é mencionado em outro livro ou documento, o que mostra claramente o caráter circunstancial de sua contribuição [a de Dryander] para o seu livro, cujo apoio se estendeu para a impressão e também como forma de divulgar um livro sobre as maravilhas do seu amigo Caspar Goldtwurm (1524-1559) Wunderzeichen, que Dryander menciona no prefácio. Goldtwurm era o superintendente (pastor) do duca de Nassau-Weilburg ao qual Dryander dedica o prefácio e o seu livro (que não menciona Staden, mas dá uma lista abundante de muitas maravilhas incríveis) pode-se ler também como uma confirmação da narrativa de Staden que várias vezes relata intervenções divinas para ajudá-lo (o vento que cessa, a pesca abundante) quando ele precisa para fazer-se mágico e manter um papel de prestígio entre os índios - método eficaz que o impediu de ser vítima da antropofagia. Essa questão da maravilha foi muito discutida na

\footnotetext{
${ }^{2}$ Para a natureza nos livros do século XVI ver Philippe Billé, La faune brésilienne, Paris: Champion, 2009.
} 
época, temos vários exemplos que mostram que no início do protestantismo não havia oposição à ideia da "maravilha", por se encontrar ainda em uma fase de definição quanto à opinião sobre essa questão. Para a estrutura do livro (junto com outra alusão no prefácio de Dryander ao humanista italiano Marzio Galeotto, que também problematizou a veracidade das maravilhas no seu livro De incognitis vulgo e não quis justificá-las por meio da religião) essa temática abriu outro assunto controverso na época com referência às experiências pessoais de Staden no Brasil que interessou muito aos seus leitores. Lembramos que apesar da proximidade a Francoforte, centro das importantes feiras de livros, existentes ainda hoje, Marburgo não foi um centro de produção de livros de viagens, sendo o de Staden o único difundido na época. Assim, o editor podia contar através do prefácio de Dryander sua proposta de ler o livro como prova de coincidências divinas, assegurar certo êxito também no campo científico.

O segundo livro de Staden (parte da edição original) vem dedicado à etnologia (provavelmente seguindo uma inspiração de Dryander como livro separado), parte que compunha um elemento científico maior. Entende-se que servia também como outra prova para a autenticidade de sua narrativa, porque suas observações, eram bem mais detalhadas que as de todos os livros disponíveis sobre o Brasil na época. O primeiro livro português sobre o Brasil, a História da Província Santa Cruz data apenas de 1576 e as cartas de Vespucci das quais tem-se várias edições não possuem detalhes etnológicos. Poucas cartas jesuítas foram publicadas em italiano e nenhuma em alemão. Dos livros de franceses apenas havia as Singularitez, de André Thevet, que foram publicadas paralelamente ao texto de Staden, em 1557/58; Léry publicou somente em 1578.

Pode-se interpretar a inclusão da folha sobre a serpente, no caso de Schmidel, como uma maneira fácil para acudir às expectativas dos leitores e uma prova de que o autor tinha interesse em saber a repercussão dos que ouviam ou liam os manuscritos da história. Certamente esses ouvintes diziam a Schmidel que a sua narrativa continha poucas histórias maravilhosas. Reconheciam talvez seu valor como manual historiográfico, com supremo valor por suas observações etnológicas sobre a região da Prata e uma das poucas fontes da época escritas por um soldado "comum" (sem alta patente militar) e não por um escrivão, um prete ou uma pessoa com função oficial ou grão militar. Mas lhes interessou também a ideia preconcebida de encontrar maravilhas da natureza nos países recém-descobertos. Nas observações sobre a natureza, Schmidel quis contentar esses críticos com a inclusão da história da anaconda e não prejudicou o objetivo do texto. Schmidel, durante a escritura, já 
considerava certas expectativas de leitores e também observou certas reticências, especialmente com relação à sexualidade das mulheres indígenas, tema que menciona, sem aprofundá-lo. Falta aqui espaço para seguir essa comparação com o texto de Schmidel que se vê nos manuscritos e que todos introduzem pequenas mudanças em seu texto, numa versão não conservada, que depois foi o modelo reproduzido em outras cópias manuscritas da época (fora o manuscrito autógrafo, há outros três exemplares até hoje; um outro existiu, mas foi extraviado) e foi base das versões impressas. Outras censuras mostram claramente o que podia parecer discutível na obra de Schmidel, certas alusões ao canibalismo numa passagem um pouco ambígua que pode referir-se ao fato que europeus talvez comiam índios durante a célebre fome de Buenos Aires e muitas outras passagens, às vezes pontos sem significado nenhum, devido às negligências de um copista. ${ }^{3}$

No caso de Staden só temos o texto final, sem a menor informação sobre o processo genético fora da menção do récit na habitual fase oral antes da escrita. Podemos também mencionar algumas informações contidas no texto como a de Dryander no prefácio sobre os altos custos das xilografias que se referem mais ao produto final do livro, mas são valiosas porque permitem pelo menos provar a intencionalidade das xilografias ao projeto do livro. Staden provavelmente pagou pelo menos uma parte desses gastos e talvez também Dryander, que os havia sugerido, e o impressor Kolbe, com as quais esperou um bom ganho porque o livro no exterior se adequava às normas de livros populares da época. A mencionada passagem sobre as xilografias não informa se Staden financiou-as totalmente, apenas menciona os altos curtos.

\section{O discurso alheio de Staden como resposta às ideias dos seus contemporâneos}

A referência a um discurso alheio pode implicar também uma pequena reserva e distanciamento com relação às ideias de outras pessoas. Staden certamente não entra nas discussões científicas sobre as ideias que os especialistas, teólogos ou cosmógrafos tinham no século XVI, por exemplo, sobre a origem dos índios (ele menciona a provável descendência de Cam, filho reprovado por Noé). Temos um caso bem claro em que um julgamento contemporâneo é rejeitado e marcado como "discurso alheio" anônimo. Deve ser interpretado com certa reticência da parte de "Staden autor" em aceitar totalmente essa ideia. Trata-se da passagem

\footnotetext{
${ }^{3}$ Para mais detalhes ver a edição crítica de Obermeier, 2008. Não existe uma edição portuguesa do Schmidel (que contém a primeira descrição de São Paulo), publicada parcialmente em Kloster / Sommer, 1942.
} 
sobre São Tomé. Staden escreve, sem mencionar São Tomé (livro 2, cap. 16) sobre Maire Humane o herói mítico dos Tupinambás: "man wil es sei eyn prophet oder apostel gewesen." (1557, p. 145). ("Têm-no por um profeta ou apóstolo"). Meire Humane é um personagem da mitologia tupi. A expressão foi também usada pelos índios para europeus, como para Staden, lendo um livro e assim atemorizando os índios (original de 1557, p. 86). Também o viajante francês André Thevet explica o costume da depilação entre os Tupinambás com referência à mitologia: "De luy ["Mair et grand Caraibe", o personagem mítico dos Tupinambás] ils apprindrent aussi à ne porter aucun poil sur eux, que celui de la teste” , Cosmographie ${ }^{4}$. Essa ideia já se encontra antes da chegada dos jesuítas na Copia der Newen Zeytung auß PresillgLand, Augsburgo [Augusta], 1514, e é retomada mais tarde em muitos documentos jesuíticos. Na História de Staden de 1557 temos o caso claramente diferente da menção de uma interpretação tradicional, mas também com certa reticência em aceitá-la. A ideia fíca no contexto do livro como uma hipótese. A razão disso é de encontrar nas ideias pessoais de Staden sobre culturas alheias não cristãs. O protestantismo da época ainda não tinha uma missão mundial, como aconteceu mais tarde, no século XIX, A falta de religião dos índios não foi nesse contexto um grande problema na época para os protestantes: os crentes foram eleitos por Deus ou não, os índios podiam ser como Staden alude: filhos de Cam, o filho reprovado de Noé (livro 2, cap.18); integraram-se assim ao sistema de uma predestinação central sobretudo ao calvinismo como graça de Deus incompreensível ao espírito do homem. Portanto, a ausência de uma predicação do Evangelho na América do Sul antes da chegada dos europeus foi um problema teológico a resolver. Talvez a lenda de São Tomé pareceu semelhante demais a histórias lendárias católicas e, por isso, Staden não a adotou com referência ao santo como também não o fez o calvinista Léry, autor da Histoire d'un voyage faict en la terre du Brésil, de 1578, tomando assim a distância típica antes da veneração de santos. Léry conhecia certamente essas lendas que menciona de maneira vaga, referindo-se também a um apóstolo. $\mathrm{O}$ caso de Léry mostra também a diferença a Staden. Mesmo se Léry não menciona São Tomé, ele utiliza uma ideia europeia sobre uma primeira missão pré-histórica na América para provar a doutrina cristã da evangelização universal da Bíblia. O mito indígena em que essa ideia de Zumé/Tomé é baseada torna-se assim um preceito literário para integrar uma avaliação religiosa negativa no texto porque, para Léry, os índios poderiam ter aceitado a religião cristã. Ao negá-la se fazem inescusáveis, sendo inexoravelmente condenados ao inferno. No meio do século XVI a ideia de uma missionarização indígena não era importante, Léry a menciona

${ }^{4}$ THEVET, 1575, p. 915 v., 1953, p. 48 
como uma possibilidade 20 anos depois, quando escreve seu livro já como pastor da igreja calvinista. Staden nem cogita essa ideia, referindo-se a valores universais humanos e da natureza quando censura os indígenas pelo seu canibalismo (1. livro, capítulo 44). Não surpreende que os missionários franceses capuchinhos na primeira colônia francesa de São Luis do Maranhão, em 1612, incluem a ideia da missionalização em seus livros. ${ }^{5}$ Eles utilizam a mesma funcionalização de Léry, como encontram uma versão desenvolvida desse mito entre os indígenas tupi do Maranhão (muitos provenientes da região de Pernambuco, fugidos da pressão dos portugueses). ${ }^{6}$

Staden não faz dos índios porta-vozes de suas ideias, eles o contradizem no que se refere aos valores da própria civilização, pensamento que Staden utiliza para integrar-se como pajé na sua civilização. A alusão do livro de Staden ao "apóstolo" mostra que ele conhecia a ideia, seja por seu contato com os portugueses e os jesuítas, seja por sugestão de alemães cultos. Não se interessou por discussões teológicas, mas se baseou sobre o empirismo da sua observação pessoal da cultura indígena. O seu julgamento sobre a religião dos índios é breve quando ele compreende as manhas de um pajé usando o ventriloquismo nas cerimônias com maracas: "Aber wie ich den betrug sahe, gieng ich zur hütten hinaus, gedachte Wie ein armes, verblentes Volck ist das.", livro 2, cap. 23): "Eu, porém, saí da cabana, quando reconheci a farsa, e pensei comigo: pobre gente cega!". Comparado com certas diatribas da época contra os índios gentios e no contexto da neutralidade de todo o seu segundo livro, esse julgamento parece como um juízo bastante discreto sobre um povo não cristão e confirma uma vez mais a importância de Staden como antropólogo e etnólogo avant la lettre. Ele é certamente mais imparcial do que as ideias do pastor calvinista Léry sobre a ausência de religião nos índios. Se conhece a opinião de Claude Lévi-Strauss que vê no livro de Léry o "bréviaire de l'éthnologue" nos seus Tristes tropiques, de 1955. Talvez essa ideia não seja tão equivocada: o estatuto de pessoa "docta" como o era um pastor formado, prescinde da situação de Staden que certamente tinha uma boa formação em língua latina na escola da cidade onde nasceu, em Homberg, na Hassia, mas não foi uma pessoa com formação clássica. Talvez tenha sido esse elemento que deixou o seu olhar sobre os índios ser um dos mais abertos para a época,

\footnotetext{
${ }^{5}$ Claude d'Abbeville, Histoire de la mission, Paris 1614; o livro de Yves d'Évreux, Suitte de l'histoire, 1615, não circulou, publicado em 1864 por Ferdinand Denis como Voyage au nord du Brésil, com as censuras do original de Paris. Estou preparando uma edição crítica do texto em francês, mais completa que a primeira edição de Ferdinand Denis de 1864, a nossa sendo baseada num exemplar (portanto com lacunas da primeira censura) de New York.

${ }^{6}$ Ver Obermeier 2005a, p. 212-214. Nova edição desse artigo acrescentado como livro previsto em 2011/2012.
} 
encantando até hoje seus leitores com a sua perspicácia e reservas diante de juízos morais unilaterais.

Léry certamente deve o seu renome muito mais ao fato de ter escrito em francês, num francês bastante apurado, e admite a sua saudade sobre as culturas Tupinambás que, foi registrado apenas 20 anos depois da viagem, quando publicou o livro em 1578, de modo memorialístico. Essa lamentação é bem comparável ao sentido de viver uma perda contínua de civilizações indígenas que também é o foco de Tristes Tropiques, de Claude Lévi-Strauss. Staden no resto foi (apesar de uma tradução bastante livre de 1837) pouco conhecido na França fora do meio de especialistas.

\section{A antropofagia}

Talvez o mais célebre exemplo de um discurso alheio seja a descrição da antropofagia. Discurso alheio porque fundamental para uma sociedade indígena desaparecida e também porque apenas dispomos de documentos de séculos anteriores que alguns pesquisadores tiveram acesso. Assim, o discurso precisa ser refeito segundo as nossas normas de compreensão. O único método para uma reconstrução etnológica pode ser uma comparação de fontes da época. Segundo elas é certo que essa prática da antropofagia existia, mesmo que até hoje historiadores tenham problemas em aceitá-la como algo de fora dos limites da própria definição do humano. Quero aqui ressaltar alguns problemas que parecem fundamentais para a compreensão dos documentos, mas foram pouco levados em consideração. Havia, como mostrei em texto anterior (Obermeier, 2001), vários discursos orais sobre o fato, o discurso francês e o discurso português, ambos mais tarde conservados por escrito. Staden posiciona-se entre os dois, tendo contato com portugueses e com franceses durante seu retorno do Brasil num navio francês e, por isso, é possível comparar as várias maneiras de descrição. O mais notável é que a descrição do "tomar nome" e da couvade não aparecem nos documentos franceses antes dos livros dos capuchinhos do Maranhão de 1612. Staden menciona o "tomar nome", mas não se refere à couvade, a qual teria descrito certamente outra singularidade incompreensível e digna de menção para seus contemporâneos. ${ }^{7}$

\footnotetext{
${ }^{7}$ Staden livro 1, cap. 22: Eynen namen mit mir machen: em fontes portuguesas (Soares de Sousa 1938, p. 394 e 399/400, Cardim 1997, p.190) temos frequentes menções do "tomar nome": a morte de um prisioneiro permitia atribuir a ele um novo nome de honra. Nas fontes francesas esse costume é registrado pela primeira vez nos livros do século XVII sobre o norte do Brasil: (Claude d'Abbeville Histoire 1614, 291 r. e Yves d'Évreux, Suitte 1615, [Exemplar de New York, 119r.] ver Obermeier 2001, p. 69-70).
} 
Um ponto que quase totalmente não aparece no discurso francês e também em Staden, mas que se encontra em vários documentos portugueses é a matança no ritual como iniciação de um jovem guerreiro. Não se pode atribuir essas diferenças puramente à falta de documentação ou ao contato com várias tribos de índios com diversos costumes. A razão tem, certamente, a ver com os vários discursos orais dos truchements, línguas ou tradutores que, com seus contos, que poderíamos chamar de récit, como a fase preparatória do livro de Staden ao qual também pertencem, preparavam, sem o saber, com suas histórias orais a documentação dos escritores. Essa documentação foi mais tarde utilizada nas Singularidades, de Thevet, e na História, de Léry. Na sua Cosmographie, Thevet aproxima-se do discurso português sobre os indígenas usando fontes orais, provavelmente de marinheiros portugueses, para a sua essencial e única descrição dos mitos tupinambás, descritos com os detalhes minuciosos, atingido apenas pela etnologia de campo 300 anos depois. Uma razão das diferenças diz respeito às concepções das pessoas observadoras. Para confirmar essa hipótese seria preciso uma detalhada comparação da literatura portuguesa da época sobre outros países como os da Ásia e da literatura sobre a educação militar para saber como certos modos de pensamento e atitudes permitiam direcionar a percepção para determinados elementos da cultura indígena numa forma exterior, conforme o pensamento português, permitindo o relevo sobre o ato da iniciação. É claro que, em certa medida, a falta de documentação não permite compreender inteiramente as diferenças de discursos, mas a consideração de discursos alheios nos livros de viagem e outros documentos da primeira fase colonial podem proporcionar uma análise das fontes mais apta a aceitar diferenças entre os documentos e impede nivelá-los para uma reconstrução de sociedades indígenas ou de seu pensamento ("la pensée sauvage", para citar outra vez Claude Lévi-Strauss). O pensamento dos indígenas era bem mais flexível e menos estável do que nos parece hoje, se analisarmos retrospectivamente. Os índios responderam a seu modo ao contato cultural, os Tupinambás adaptaram os europeus como sendo personagens de seus mitos, como nos mostra esse mito muito disperso na América do Sul até hoje sobre heróis culturais que, na versão tupinambá, com uma interpretação cristã sobre o fator civilizador do cristianismo, nos apresentam Jean de Léry e Claude d'Abbeville. Os europeus, por outro lado, focalizavam a sua descrição de culturas alheias em crenças secundárias que se assemelhavam ao cristianismo (Tupã era um demônio secundário para os Tupis) ou em fatos que enfatizam o caráter alheio dos indígenas (a antropofagia, difundida como costume, mas provavelmente muito menos recorrente do que alguns viajantes nos sugerem). 


\section{Reticências}

Há também o caso de um discurso alheio existente que um autor não considera em sua própria escritura. Em poucos casos pode ser por ignorância, mas para um autor tão sutil como Staden é uma escolha consciente de fatos. Ele admite numa passagem na Beschlussrede final $^{8}$ que poderia ter escrito muito mais fatos que não cabiam no seu trabalho literário (e nas expectativas dos leitores). "Poderá alguém dizer que eu devia talvez fazer imprimir tudo quanto conheci e vi. Precisava então escrever um livro grosso. Decerto tinha eu também muito mais para escrever, se para tanto me esforçasse, mas o meu intuito não era esse", usando o tópico habitual da "brevitas" na retórica. Sabemos de muitos outros documentos da época, inclusive pelo livro de Staden, que entre os Tupinambás era costume dar ao prisioneiro uma mulher da tribo, e não há razão para crermos que com Staden tenha sido diferente. Ele menciona esse costume de forma expressa também em seu capítulo sobre a antropofagia no segundo livro ${ }^{10}$. Sua relação com uma mulher da tribo indígena provavelmente foi omitida em decorrência de sua própria avaliação moral como autor para os seus leitores cristãos. A sexualidade extraconjugal ainda hoje faz parte dos tabus da cultura cristã e teria comprometido a recepção do texto da comiseração moral e da prova de bondade de Deus para os leitores que Staden quis atingir com sua escritura edificante. O discurso ao qual Staden aqui se nega a considerar entra pela porta dos fundos como observação neutral e etnológica da qual ironicamente ele mesmo usa no segundo livro. Staden talvez deixou intencionalmente essa discrepância no texto, para que um leitor inteligente possa percebê-la.

\section{Conclusão}

A nossa análise tem mostrado que as "camadas" do texto de Staden e o seu trabalho literário para fazer de um récit oral um discurso centrado no leitor têm uma importância maior para a compreensão do texto. Reconstruir esse discurso através da comparação com outros documentos da época e a consideração exata de procedimentos literários e tradições de gêneros e expectativas do leitor pode contribuir para uma melhor compreensão não apenas na obra de Staden, mas em muitos textos importantes entre os gêneros literários próprios e textos

\footnotetext{
${ }^{8}$ STANDEN, 1557, p. 175.

${ }^{9}$ Conclusão, ed. Obermeier, 2007, p. 403.

${ }^{10}$ STADEN, 1557, p. 157
} 
historiográficos. Apenas com essa reconstrução do cruzamento de discursos se pode mostrar como esses autores aprendiam algo sobre a cultura indígena, comparando e valorizando discursos orais e, em alguns casos, escritos da época com as próprias experiências. No processo da elaboração de livros (ou das ilustrações deles) esse discurso se sobrepõe a outra seleção, religiosa no caso de Léry, de observador neutro e narrador edificante no caso de Staden. Só a detalhada análise desses processos de percepção, comparados a discursos alheios e a transformação do vivido em escrito ou desenho permite aprofundar nosso saber sobre os primeiros livros de viagens.

\section{Bibliografia}

\section{Fontes}

CARDIM, Fernão: Tratados da terra e gente do Brasil, ed. Ana Maria de Azevedo, Lisboa: Commissão nacional para as comemorações dos descobrimentos portugueses 1997, 2.ed. 2000.

CLAUDE < d'Abbeville > : Histoire de la mission des peres capucins en l'isle de Maragnan et terres circonvoisines ou est traicte des singularitez admirables \& des meurs merveilleuses des Indiens habitants de ce pais avec les missives et advis qui ont este enuoyez de nouveau, Paris, François Huby, 1614. [viii], 394/5, [17].

Versão digital (seconde impression 1614) http://gallica.bnf.fr/

CLAUDE < d'Abbeville>: Histoire de la mission des peres capucins en l'isle de Maragnon et terres circonvoisines, Paris 1614, éd. par Alfred Métraux et Jacques Lafarge (Frühe Reisen und Seefahrten in Originaltexten 4), Graz 1963.

CLAUDE < d'Abbeville>: Historia da missão dos padres capuchinhos na illa do Maranhao e suas circumvisinhansas, trad. por Cezar Augusto Marques, São Luis do Maranhão: Freitas 1874.

CLAUDE <d'Abbeville>: Histoire de la mission, [com a colaboração de Rodolfo Garcia], Coleção Eduardo Prado, São Luis 1922.

CLAUDE < d'Abbeville>: Historia da missão dos Padres Capucinhos na Ilha do Maranhão e terras circumvizinhas; em que se trata das singularidades admiráveis e dos costumes estranhos dos índios habitantes do país, tradução de Sérgio Millet, introdução e notas de Rodolfo Garcia, São Paulo 1945, nova ed.: (Coleção Reconquista do Brasil, $1^{\text {a }}$ Série, dir. por Mário Guimarães Ferri, Belo Horizonte: Itatiaia: Ed. da universidade de São Paulo; 19), 1975.

COPIA DER NEWEN eytung auß Presilg Landt, Augspurg: Öglin, [1515],, Microfilme 1304/3376 da série Flugschriften des frühen 16. Jahrhunderts ed. Hans-Joachim Köhler; Hildegard Hebenstreit-Wilfert, Zug: Inter Documentation Co. 1979-1987. [ver também Schuller] 
Gândavo, Pêro de Magalhães de: Regras que ensinam a maneira de escrever e a ortografia da língua portuguesa: com o diálogo que adiante se segue em defensão da mesma língua, ed. facsimilada da 1. ed., [Lissabon: Antonio Gonsalvez] 1574, Lisboa: Biblioteca Nacional 1981.

The histories of Brazil, 1576, Facimile da ed. História da provincia sancta Cruz,Lisboa: Antonio Gonsalvez 1576 con tradução em inglês por John Batterson Stetson, (Documents and narratives concerning the discovery and conquest of Latin America; 5), New York: Cortes Society 1922, Reprint: New York: Kraus 1969.

- Tratado da província do Brasil, reprod. facs. do ms. n. 2026 da bibl. Sloaniana do Museu Britânico; introd. leitura; comentários e indice de vocábulos Emmanuel Pereira Filho, (Dicionário da língua portuguêsa; 5), Rio de Janeiro: Inst. Nacional do Livro 1965.

GALEOTTO, Marzio: De incognitis vulgo/Quel che i più non sanno, a cura di Mario Frezza, con prefazione di Giuseppe Toffanin, (Collezione umanistica; 2), Neapel: Pironti 1948.

GOLTWURM, Caspar: Wunderwerck vnd Wunderzeichen Buch, Frankfurt am Main: David Zephelius 1557, online: http://www.obrasraras.usp.br/obras/000154/

LERY, Jean de. Histoire d'un voyage fait en la terre du Brésil, [Facsimile da edição Genebra: Chuppin $1580^{2}$ ], éd de Jean Claude Morisot et Louis Necker, (Les classiques de la pensée politique; 9), Genève: Droz 1975

PEREIRA, Luiz Alberto [Diretor]: Hans Staden, um film de Luiz Alberto Pereira. [actores.:] Carlos Evelyn, Ariana Messias [...], São Paulo: Versátil Home Video, DVD-Video (92 min.)

SCHMIDEL, Ulrich [Schmidt, Ulrich]: Wahrhafftige und liebliche Beschreibung etlicher fürnemen Indianischen Landtschaften und Insulen die vormals in keiner Chroniken gedacht und erstlich in der Schiffart Ulrici Schmidts von Straubingen mit grosser gefahr erkundigt und von ihm selber auffs fleissigt beschrieben und dargethan, in: Sebastian Franck: Weltbuch, 2. tomo com o título: Ander theil dieses Weltbuchs von Schiffarten, Warhafftige Beschreibunge aller und mancherley sorgfeltigen Schiffarten, auch viler unbekanten erfundnen Landtschafften, Insulen, Königreichen und Stedten [...] durch Ulrich Schmidt von Straubingen, gedruckt zu Franckfurt am Mayn, Anno 1567, 1-59. Desse último existem exemplares com o frontispício: Neuwe Welt: Das ist, Warhafftige Beschreibunge aller schönen Historien von erfindung viler vnbekanten Königreichen, Landschafften, Jnsulen vnnd Stedten, von derselbigen gelegenheit, wesen, bräuchen [...]; durch Ulrich Schmid von Straubingen und andern mehr, so in eigner Person gegenwertig gewesen, Frankfurt/M: Feirabend und Hüter, 1567 [impressor: Lechler]

. Viaje al Rio de la Plata: 1534-1554, notas bibliográficas y biográficas for Bartolomé Mitre, prólogo, traducción y anotaciones por Samuel A. Lafone Quevedo, (Biblioteca de la Junta de Historia y Numismática Americana; 1), Buenos Aires: Cabaut 1903

Schmidel, Ulrich /Schmidl, Ulrico: Reise in die La Plata-Gegend (1534-1554)/ Viaje al Río de la Plata y Paraguay, (Fontes Americanae, 3), kritische Ausgabe / edición crítica von Franz Obermeier, Kiel: Westensee-Verlag 2008, ISBN 3-931368-16-6. 
.Ulrich Schmidel/Ulrico Schmidl: Reise in die La Plata-Gegend (1534-1554), Das Stuttgarter Autograph in moderner Fassung, bearbeitet und kommentiert von Franz Obermeier, (Straubinger Hefte, 58), Straubing 2008, ISSN 0562-164-X.

SOARES, Francisco De algumas cousas mais notaveis do Brasil (Informação jesuitica de fins do seculo XVI) in: Revista do Instituto historico e geografico brasileiro, tomo 94, Vol. 148, 1923,. Rio de Janeiro 1927, 367-421. Nova ed.: Coisas notáveis do Brasil, [edição preparada por A. G. Cunha] (Dicionário da língua portuguesa. Textos e vocabulários; 6), Rio de Janeiro: Instituto Nacional do Livro, Ministério da Educação e Cultura, 1966.

STADEN, Hans: Warhaftige//Historia und beschreibung eyner Landt-//schafft der Wilden/ Nacketen/Grimmigen Menschenfresser//Leuthen/in der Newenwelt America gelegen/vor und nach //Christi geburt im Land zu Hessen unbekant/biß uff dise ij.//nechstvergangene jar/Da sie Hans Stadens von Hom-//berg auß Hessen durch sein eygne erfarung erkant/und yetzo durch den truck an tag gibt.// [...] Getruckt zu Marpurg/im jar M.D. LVII. editio princeps com colofone: ,uff Fastnacht“, nova edição outono 1557: „vff Mariae Geburts tag”.

EDIÇÃO da feira de primavera:,,uff Fastnacht“" [carnaval].

http://gdz.sub.uni-goettingen.de/en/

http://www.obrasraras.usp.br/obras/000152/

EDIÇÃO da feira de outono: „,vff Mariae Geburts tag“ [dia de S.Maria] http://www.bn.br na Biblioteca digital.

Warhaftige Historia. Zwei Reisen nach Brasilien, (1548-1555) / Historia de duas viagens ao Brasil. Kritische Ausgabe / edição crítica: Franz Obermeier, Übertragung ins heutige Deutsch: Joachim Tiemann. Tradução ao português: Guiomar Carvalho Franco. Revisão: Augusto Rodrigues, (Fontes Americanae, 1), Kiel: Westensee-Verlag 2007 ISBN: 978393136870X. (com o facsimile de Hans Staden, Warhaftige Historia, Marburg 1557).

Véritable Histoire et description d'un pays habité par les hommes sauvages, nus féroces et anthropophages (Voyages, relations et mémoires originaux pour servir à l'histoire de la découverte de l'Amérique, 3), publiés par Henri Ternaux-Compans, Paris 1837.

.True History, ed. Neil Whitehead e Michael Harbsmeier, Durham: Duke University Press 2008.

THEVET, André. Cosmographie de Levant, éd. de Frank Lestringant, [Facsimile da edição Lyon: Tournes et Gazeau 1556], Genève: Droz 1985

Les singularités de la France antarctique, facsimilé de l'édition de [Paris: Maurice de La Porte] 1558, éd. de Pierre Gasnault, intr. de Jean Baudry, Paris: Le Temps 1982.

. Cosmographie universelle, 2. Bde., Paris: Guillaume Chaudiere 1575.

. Les vrais pourtraicts et vies des hommes illustres. Paris: Veuve Keruert et Chaudiere 1584, Faksimile ed por Rouben C. Cholakian, New York: Scholar's Facs. and Repr. 1973.

. Les Français en Amérique pendant la deuxième moitié du XVI siècle, Le Brésil et les 
Brésiliens par A. Thevet, éd. par Suzanne Lussagnet (Pays d'outre mer, Deuxième série, Les classiques de la colonisation), introduction par Charles André Julien, Paris: PUF 1953.

. Histoire d'André Thevet Angoumoisin, Cosmographe du Roy, de deux voyages par luy $\overline{\text { faits }}$ aux Indes Australes, et Occidentales, ed. critique par Jean-Claude Laborie, (Travaux d'humanisme et renaissance; 416) Genève: Droz 2006.

YVES <d'Évreux>: Voyage dans le nord du Brésil par le Père Yves d'Évreux publié d'après l'exemplaire unique conservé à la bibliothèque impériale de Paris, avec une introduction et des notes par Ferdinand Denis, (Biblioteca americana, collection d'ouvrages inédits ou rares sur l'Amerique), Leipzig/Paris: Franck 1864 Versão digital: http://purl.pt/115 e http://gallica.bnf.fr/ark:/12148/bpt6k5732857p.r=claude+d\%27abbeville.langEN.

Viagem ao norte do Brasil feita nos anos de 1613 a 1614, com introdução e notas por Ferdinand Diniz [!], traduzida pelo Dr. Cezar Augusto Marques, Maranhão 1874, nova edição: Rio de Janeiro 1929, $3^{\text {a }}$ edição anotada aos cuidados de Sebastião Moreira Duarte, São Paulo 2002, a ed. de 1874 disponível através Google. Facsimile da ed. 1874: Ithaca: Cornell University Library, 1991.

Voyage dans le nord du Brésil fait durant les années 1613-1614, éd. par Hélène Clastres, Paris 1985 [extratos da edição de 1864 com ortografia modernizada].

- Continuação da história das coisas mais memoráveis acontecidas no Maranhão nos $\overline{a n o s}$ de 1613 e 1614, tradução de César Augusto Marques (Edições do Senado; 94), Brasília, DF: Senado Federal, 2007.

História das coisas mais memoráveis, ocorridas no Maranhão nos anos de 1613 e 1614, apresentação da coleção: Fundação Darcy Ribeiro; introdução geral: Carlos de Araújo Moreira Neto; introduções, Ferdinand Denis (e notas), Gabriel Marcel, Mércio Pereira Gomes; tradução: équipe de Marcella Mortara; revisão da tradução, Vera A. Harvey, (Coleção Franceses no Brasil; 4), Rio de Janeiro: Fundação Darcy Ribeiro 2009. [com as passagens do manuscrito de New York]

- Voyage au nord du Brésil (1613-1614), ed. du texte complet établi par Franz Obermeier, Kiel: Westensee-Verlag 2011 (ainda não publicado)

\section{Literatura de pesquisa}

BAISCH, Martin: Indexikalität und Neugier in Hans Stadens Brasilien-Bericht, in: Dynamiken des Wissens, ed. Klaus W. Hempfer e Anita Traninger, Freiburg: Rombach 2007, 163 185.

BAKHTINE, Mikhail: Problemy tvorčestva Dostoevskogo, 1929, na versão revisada com o título Problemy poètiki Dostoevskogo, 1963. Não existem traduções em português, em francês: La poétique de Dostoiëvski, de Mikhaïl Bakhtine, trad. de Isabelle Kolitcheff, Paris: Éd. du Seuil 1998.

BÔAS, Luciana Villas: Travel Writing and Religious Dissent, Hans Staden's 'Warhaftig Historia' in Print, Dissertation Columbia University 2006. 
. Wild stories of a pious travel writer: the unruly example of Hans Staden's Warhaftig Historia (Marburg 1557), in: Daphnis, 2004, 187-212.

The Anatomy of Cannibalism: Religious Vocabulary and Ethnographic Writing in the Sixteenth Century, in: Studies in Travel Writing, 2008, 7-27.

BILLE, Philippe: La faune brésilienne, (Géographies du Monde, 12), Paris: Champion 2009 (Dissertation Bordeaux 2000).

BÜTTNER, Nils: Bilder von „Grimmigen Menschenfresser Leuthen“ - Von der Autopsie zum Topos, in: Passion, Affekt und Leidenschaft in der Frühen Neuzeit, (Wolfenbütteler Arbeiten zur Barockforschung; 43), ed. Johann Anselm Steiger, 2 Bde., Wiesbaden: Harrassowitz 2005, Bd.2, 889-917.

CASTRO, Eduardo Batalha Viveiros de: From the enemy's point of view, humanity and divinity in an Amazonian society, translated by Catherine V. Howard, Chicago: Univ. Press 1992 [Araweté, os deuses canibais, Rio de Janeiro: Zahr 1988]

DOMSCHKE, Rainer / OBERMEIER, Franz (ed.): Publicações sobre o Brasil em língua alemã, Deutschsprachige Brasilienliteratur 1500-1900, Resenha bibliográfica, Bibliografisches Verzeichnis, São Leopoldo: OIKOS-2011.

FERNANDES, Florestan: La guerre et le sacrifice humain chez les Tupinamba, in: Journal de la société des americanistes de Paris, 1952, 139-220.

HANENBERG, Peter: Hans Staden, Legende einer Reise ins Brasilien des 16. Jahrhunderts, in: Portugal-Alemanha-Brasil, actas do VI. Encontro Luso-Alemão/6.Deutsch-Portugiesisches Arbeitsgespräch 2001, ed. António Henrique de Oliveira Marques (Colecção Hespérides Literatura; 14), 2 tomos, Braga 2003, tomo 2, 57-64.

HARBSMEIER, Michael: Elementary structures of otherness, an analysis of sixteenth century German travel accounts, in: Voyager à la Renaissance, ed. Jean Céard et Jean-Claude Margolin, (Actes du Colloque de Tours 1983), Paris 1987, 337-356.

. Writing and the other: travellers' literacy, or towards an archaeology of orality, in: Literacy and society, ed. Karen Schousboe, Kopenhagen 1989, 197-228.

. Wilde Völkerkunde, andere Welten in deutschen Reiseberichten der Frühen Neuzeit, (Historische Studien; 12), Frankfurt: Campus-Verlag 1994

. Vom Nutzen und Nachteil des Studiums älterer Reiseberichte: zur Wiederentdeckung Hans Stadens im 19. und 20. Jahrhundert, in: Die Wiederentdeckung Lateinamerikas, die Erfahrung des Subkontinents in Reiseberichten des 19. Jahrhunderts, ed. Walther L. Bernecker (Lateinamerika-Studien; 38), Frankfurt: Vervuert 1997, 79-105.

HOLDENRIED, Michaela: Künstliche Horizonte, Alterität in literarischen Repräsentationen Südamerikas, (Philologische Studien und Quellen; 183), Berlin: Campus-Verl. 2003. 
KIENING, Christian: Alterität und Mimesis; Repräsentation des Fremden in Hans Stadens Historia, in: Nach der Sozialgeschichte: Konzepte für eine Literaturwissenschaft zwischen Historischer Anthropologie, Kulturgeschichte und Medientheorie, ed. Martin Huber e Gerhard Lauer, Tübingen: Niemeyer 2000, 483-507.

KLOSTER, Wilhelm/SOMMER, Friedrich: Ulrico Schmidl no Brasil quinhentista, (Publicações da Sociedade Hans Staden; 4), tradução do alemão: Georg August Buechler, São Paulo 1942.

LESTRINGANT, Frank: André Thevet: cosmographe des derniers Valois, (Travaux d'humanisme et renaissance; 251), Genève: Droz 1991 (Paris, Diss., 1988).

. Le Huguenot et le sauvage: l'Amérique et la controverse coloniale, en France, au temps des Guerres de Religion (1555-1589), (Littérature des voyages; 5), Paris 1990, 3.ed. (Titre courant; 27), Genève 2004.

LEVI-STRAUSS, Claude: Tristes tropiques, Paris: Plon 1955.

MENK, Gerhard: Die beiden Widmungsschreiben Hans Stadens an die Grafen von Waldeck und Hanau, in: Zeitschrift des Vereins für hessische Geschichte und Landeskunde, 1989, 63-70.

MENNINGER, Annerose: Die Macht der Augenzeugen, Neue Welt und Kannibalen-Mythos, 1492-1600, (Beiträge zur Kolonial- und Überseegeschichte; 64), Stuttgart: Steiner 1995.

METCALF, Alida C.: Go-betweens and the colonization of Brazil 1500-1600, Austin: University of Texas Press 2005.

METRAUX, Alfred: Les migrations historiques des Tupi-guarani, in: Journal de la société des Américanistes de Paris, nouvelle série 1927, 1-45.

La Religion des Tupinamba et ses rapports avec celle des autres tribus tupi-guarani, (Bibliothèque de l'Ecole des Hautes Etudes, Sciences religieuses; XVI), Paris: Leroux 1928 [1928a].

. La Civilisation matérielle des tribus Tupi-Guarani, Paris: Geuthner 1928 [1928b].

. Les précurseurs de l'ethnologie en France du $\mathrm{XVI}^{\mathrm{e}}$ au $\mathrm{XVII}^{\mathrm{e}}$ siècle, in: Cahiers d'histoire mondiale, 1963, 721-738. [1963a].

. The Tupinamba, in: Handbook of South American Indians ed. Julian Haynes Steward, Tomo 3: The tropical forest tribes, New York 1963, 45-133. [1963b].

. Religión y magias indígenas de America del Sur, edición postuma establecida por Simone Dreyfus; traducción del francés por Miguel Rivera Dorado, Madrid: Aguilar 1973.

MILBRADT, Hilmar: Zu einem bisher unbekannten Brief des Hans Staden von Homberg in Hessen an den Grafen Wolrad von Waldeck, in: Hessische Heimat, Marburg, Jahrgang 6, Heft $5,1956 / 57,27-28$. 
NEUBER, Wolfgang: Fremde Welt im europäischen Horizont, zur Topik der deutschen Amerika-Reiseberichte der Frühen Neuzeit, (Philologische Studien und Quellen; 121), Berlin: Schmidt 1991

OBERMEIER, Franz: Französische Brasilienreiseberichte im 17. Jahrhundert, Claude d'Abbeville: Histoire de la mission; Yves d'Evreux: Suitte de l'histoire, Bonn: Romanist. Verlag 1995, (Regensburg, Univ. Diss, 1994).

. Bilder von Kannibalen, Kannibalismus im Bild, brasilianische Indios in Bildern und Texten des 16. Jahrhunderts, in: Jahrbuch für Geschichte Lateinamerikas, 38.2001, 49-72. Online: http://www-gewi.uni-graz.at/jbla/

.Transposições e interrelações de géneros na iconografia do século dos descobrimentos, in: Lusorama 55/56, 2003, 44-88.

A percepção e a representação do espaço nos primeiros documentos sobre Argentina e Brasil no século XVI, in: História Unisinos, Dossiê América Latina Colonial, Universidade do Vale do Rio dos Sinos, Programa de pós-graduação em história, Número 9, volume 8, 2004, 33-61.

. Documentos sobre a colônia francesa no Maranhão (1612-1615): as partes censuradas do livro de Yves d'Évreux "Suitte de l'histoire", in: História do Maranhão: Novos Estudos, ed. Wagner Cabral da Costa, Departamento de História da Universidade Federal do Maranhão, São Luis 2004, 30-50.

Documentos inéditos para a história do Maranhão e do nordeste na obra do capuchinho francês Yves d'Evreux Suitte de l'histoire (1615) in: Boletim do Museu Paraense Emílio GOELDI, Série Ciências humanas, vol.1, nr.1, 2005, Janeiro-Abril, 195-251. [2005a], online: http://scielo.iec.pa.gov.br/pdf/bmpegsch/v1n1/v1n1a09.pdf

Identidades latinoamericanas no século dos descobrimentos: pontos de encontro e divergências nas definições de identidade indígena e europeia, in: Fronteiras e identidades, identidades e fronteiras, ed. Klaus-Dieter Ertler e Enrique Rodrigues Moura, Frankfurt: Lang 2005, 17-43. [2005b].

. Der argentinische Erstdruck Nierembergs De la diferencia in Guarani im Kontext der Bilderzyklen in Lateinamerika im 18. Jahrhundert, Online-Publikation UB Heidelberg, ARTDok, 2006. URN: urn:nbn:de:bsz:16-artdok-1548; URL: http://archiv.ub.uniheidelberg.de/artdok/volltexte/2006/154/

. As relações entre o Brasil e o La Plata no século XVI nos primeiros documentos sobre Assunção (Asunción) e Santa Catarina, in: Jahrbuch für Geschichte Lateinamerikas, 43.2006, 317-341. Disponível online em: http://www-gewi.uni-graz.at/jbla/volltexte.html\#06

. Bibliografia de Hans Stadens in: Unter Menschfresser-Leuthen/Entre as gentes antropófagas; Hans Stadens Brasilienbuch von 1557/O livro de Hans Staden de 1557, hrsg. von/editado por Sven-Hinrich Siemers, Texte: Wolfgang Schiffner in Zusammenarbeit mit/em colaboração com Eckhard E. Kupfer, Franz Obermeier \& Sven-Hinrich Siemers, 
(Regionalmuseum Wolfhager Land, Sonderausstellungen, 5), Wolfhagen: Regionalmuseum Wolfhager Land, 2007. [2007a]

. A construção de identidade e diferença de europeus e índios na iconografia latinoamericana dos séculos XVI e XVII, in: Estrategias de la hibridez en América Latina, del descubrimiento al siglo XXI, ed. por Alfonso de Toro, Frankfurt: Lang 2007, congresso Regensburg 83-116. [2007b].

La colonie française au Maranhão (1612-1615), l'importance d'un épisode colonial oublié, in: Jean Yves Mérian (Hrsg.), Les aventures des Bretons au Brésil à l'époque coloniale (Collection Bretons à travers le monde), congresso Rennes 2005, Rennes: Portes du Large 2007, 127-149. [2007c].

Indigenous letters in colonial Brazil: a Tupi-correspondence during the Dutch Wars in $\overline{1645} / 1646$, congress Bielefeld, ed. Rosa Yañez, Barbara Job, Sebastian Thies, Rosa Yañes Rosales, não publicado.

. Yves d'Evreux e a fundação de São Luís - Documentos inéditos sobre o Maranhão em $\overline{1615}$, Imperatriz: Ética 2011 ainda não publicado.

. Historiographie als koloniale Zeitgeschichte im 16. Jahrhundert, Ulrich Schmidel und sein Bericht über die Eroberung des La Plata-Raums, in: Zwischen Wissen und Politik, ed. Frank Bezner e Kirstin Mahlke, Akademie der Wissenschaften Heidelberg 2006, ainda não publicado.

RAAK TENHUISEN, Dwight R.: Providence and passio in Hans Staden's Wahrhaftig [sic] Historia, in: Daphnis, 2004, 213-254.

SANTANA, Vanete Dutra: Lobato e os carrascos civilizados, a construção de brasilidade via reescritura de Warhaftige Historia, de Hans Staden, Dissertation, Universidade Estadual de Campinas 2007, http://libdigi.unicamp.br/document/?code=vtls000416829

SANTOS-LOPES, Marília dos: Hans Staden a "verdadeira história" de uma viagem ao Brasil no século XVI, in: Portugal-Alemanha-Brasil, actas do VI. Encontro Luso-Alemão/6.Deutsch-Portugiesisches Arbeitsgespräch 2001, ed. António Henrique de Oliveira Marques, (Colecção Hespérides Literatura; 14), Braga 2003, tomo 2, 45-55.

SCHLECHTWEG-JAHN, Ralf: The Power of Cannibalisation. Hans Staden's American Travels Account of 1557, in: The Propagation of Power in the Medieval West, selected Proceedings of the International Conference Groningen 1996, ed. Martin Gosman, (Mediaevalia Groningana; 23), Groningen 1997, 419-437.

SCHULLER, Rudolf: A Nova gazeta da terra do Brasil (Newen zeytung auss Presillg landt) e sua origem mais provavel; com a traducção portugueza e a reproducção em fac-simile do precioso pamphleto pertencente á Bibliotheca nacional do Rio de Janeiro: , 1914 (extrato das Annaes da Bibliotheca nacional Rio de Janeiro, Nr.33.1911, Disponível on-line em http://objdigital.bn.br/acervo_digital/anais/anais.htm.

SMITH, Duncan: "beschreibung eyner Landtschafft der Wilden/Nacketen/Grimmigen 
Menschenfresser Leuthen", the German image of America in the sixteenth century, in: The German contribution to the building of the Americas, Studies in honor of Karl J. R. Arndt, ed. Gerhard K. Friesen e Walter Schatzberg, Hanover (New Hamps.) 1977, 1-19.

TOSCANO DEL BANNER, Andreas: Frühe Darstellungen Amerikas, Hans Stadens "Wahrhaftige Historia", in: Staden Jahrbuch, 1989/90, 50-73.

WAGNER, Sabine: Zwischen Paraíba und Acheron, die Überlieferung der Reiseberichte des 16. Jahrhunderts im Barock, in: Von der Weltkarte zum Kuriositätenkabinett, Amerika im deutschen Humanismus und Barock, ed. Karl Kohut, (Americana eystettensia, Serie A., Kongressakten; 14), Frankfurt: Vervuert 1995, 58-77.

WENDT, Astrid: Kannibalismus in Brasilien, (Europäische Hochschulschriften Reihe Ethnologie et anthropologie sociale; 15), Frankfurt: Lang 1989 (Diss. Tübingen).

ZIEBELL-WENDT, Zinka: Relatos quinhentistas sobre o Brasil: humanistas, pastores e mercenários numa terra de canibais, Mikrofiche, Berlin 1994, (Berlin, FU, Diss.,), publicado em forma de livro como: Terra de canibais, Porto Alegre: UFRGS 2002.

[Recebido em março de 2011 e aceito para publicação em abril de 2011]

How to learn about indigenous cultures in colonial times: Hans Staden's Historia 1557; textual history and a controversial debate about contemporary discourses

Abstract: The travel narrative of the German Hans Staden, Warhaftige Historia, the first book published about Brazil in 1557, is a major source for our knowledge about colonial Brazil and its indigenous civilizations, mainly the Tupinambá. This contribution shows that the observations in the book are corresponding to reality, and that the author conceives his narrative also as an answer to "foreign discourses", moral evaluations about the indigenous people and religious views about them in a critical manner.

Keywords: Hans Staden Warhaftige Historia; True History, Marburg 1557

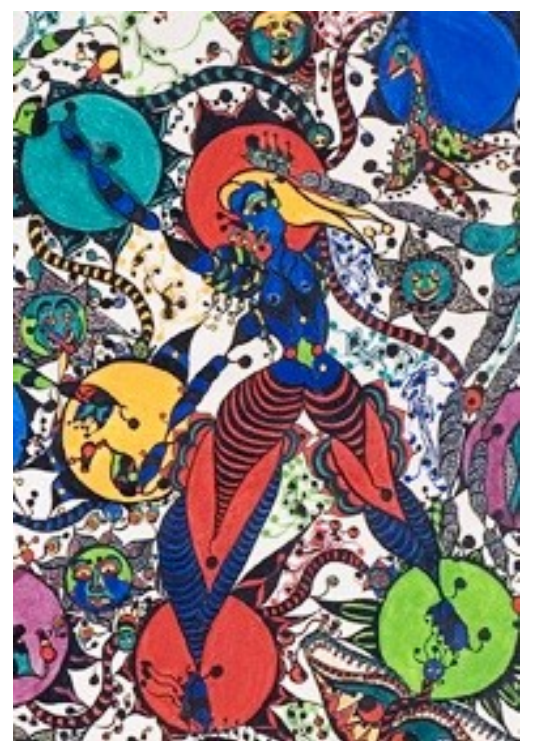

